\title{
Preparation of Early Intervention Personnel in a Rural State
}

\author{
Sarah Rule \\ Barbara Fiechtl \\ Lisa Huntington \\ Utah State University \\ Developmental Center for Handicapped Persons
}

$\mathbf{T}$ he passage of Public Law 99-457, the Education of the Handicapped Amendments of 1986, created an urgent need to prepare personnel to serve preschool children with disabilities. Several provisions of the law pertain to this need. First, the law requires that states establish standards to assure that qualified personnel serve these children. Second, children with disabilities aged 3 to 5 must be provided with a free and appropriate public education, creating an immediate need for early childhood special education teachers and related service personnel. Finally, the law permits states to serve children aged birth through 2 years who have identified disabilities or are at risk for later development of handicaps. By the fall of 1988, all states and eight districts, territories, and trusts had planned to serve this age group (Brown, Campbell, Thiele, \& Hebbelar, 1988). The agency that provides these services is governor-appointed and may or may not be a department of education. For this reason, and because the law and current practice require that teams representing a variety of disciplines provide service, early intervention personnel must be trained to work with teams of professionals and parents.

In Utah, as in many states, services were provided to some preschoolers with handicaps prior to the passage of P.L. 99-457. In 1988 , the Departments of Health and Education assumed responsibility for services. Hence, experienced personnel (those who served preschoolers with disabilities prior to 1988) are now employed by these different agencies. If they are teachers, they must acquire training by 1995 to meet the requirements of a newly-established preschool handi- capped teacher certificate (Utah State Board of Education, 1989). Institutions of higher education and state agencies must provide training to existing and new personnel to assure a continuing supply of qualified personnel.

The challenge to prepare qualified earlyintervention personnel is not unique to Utah. Prior to the passage of P.L. 99-457 most states reported a shortage of early-intervention personnel (Meisels, Harbin, Modigliani, \& Olson, 1988). In rural states, this challenge compounds the already-critical need for special educators regardless of specialty (e.g., Helge, 1987). This paper describes how information about training competencies was collected in Utah and how one university developed a program to deliver training to personnel across geographic regions.

\section{Survey of Early Intervention Service Providers}

To plan the education of personnel to serve young children with handicaps, the Utah State Office of Education contracted for a survey conducted by the Early Intervention Research Institute at Utah State University. The survey examined staff characteristics and opinions regarding certification. Conducted prior to the implementation of P.L. 99-457, the survey was addressed to 28 programs offering educationally-based direct service to children with handicapping conditions and/or those at risk in the age range from birth to 5 years. Head Start agencies and diagnostic services were not included in this sample. Two surveys were returned by mail. To complete the surveys in a timely fashion, responses of 23 programs were collected via telephone interview. Three programs did not respond, yielding a response

\begin{abstract}
There is a critical need to prepare early-intervention personnel resulting from the passage of the Education of the Handicapped Act Amendments of 1986. This paper presents the results of a survey of service providers regarding the competencies they considered essential to serve young children with disabilities. It also describes the organization of a program to prepare personnel in a rural state where persons who need preparation may not have access to on-campus training.
\end{abstract}


rate of $93 \%$. The respondents included 15 rural programs, 9 urban, and 1 that provided service in both areas.

\section{Instrument}

The survey consisted of both open-ended and forced-choice questions addressing a number of areas. Four questions were pertinent to this paper. Two asked program directors to (a) specify the program requirements (if any) for certification, and (b) indicate whether they perceived that certification would be advantageous. Two asked them to rank order a list of knowledge and ability competencies that might be required of early intervention personnel. The survey authors developed the list.

\section{Results}

The responses of urban and rural programs were analyzed separately. When responses did not differ between the two groups of re- spondents, the data were combined for purposes of discussion.

\section{Certification Status}

The majority of programs in Utah $(56 \%)$ required some type of certification (e.g., special education, early childhood education) for their staff prior to the passage of P.L. 94-457. There was, however, a significant difference between the viewpoints of rural and urban directors with respect to certification. Ninety percent of urban programs reported that certification was a requirement for employment, while only $33 \%$ of the rural programs made this mandatory $\left[\left(X^{2}(1)\right.\right.$ $-6.4, \underline{p}<.05)$.] Forty-seven percent $(47 \%)$ of the rural programs reported that certification was either unnecessary or that they were unsure of its necessity. Twenty percent $(20 \%)$ said certification should not be required. Thus, Utah's new certification requirements affect a significant proportion of the current work force. Their effect is greatest upon rural programs.

Figure 1: Program Directors' Ratings of Desirable Knowledge Competencies for Staff by Age of Children Served.

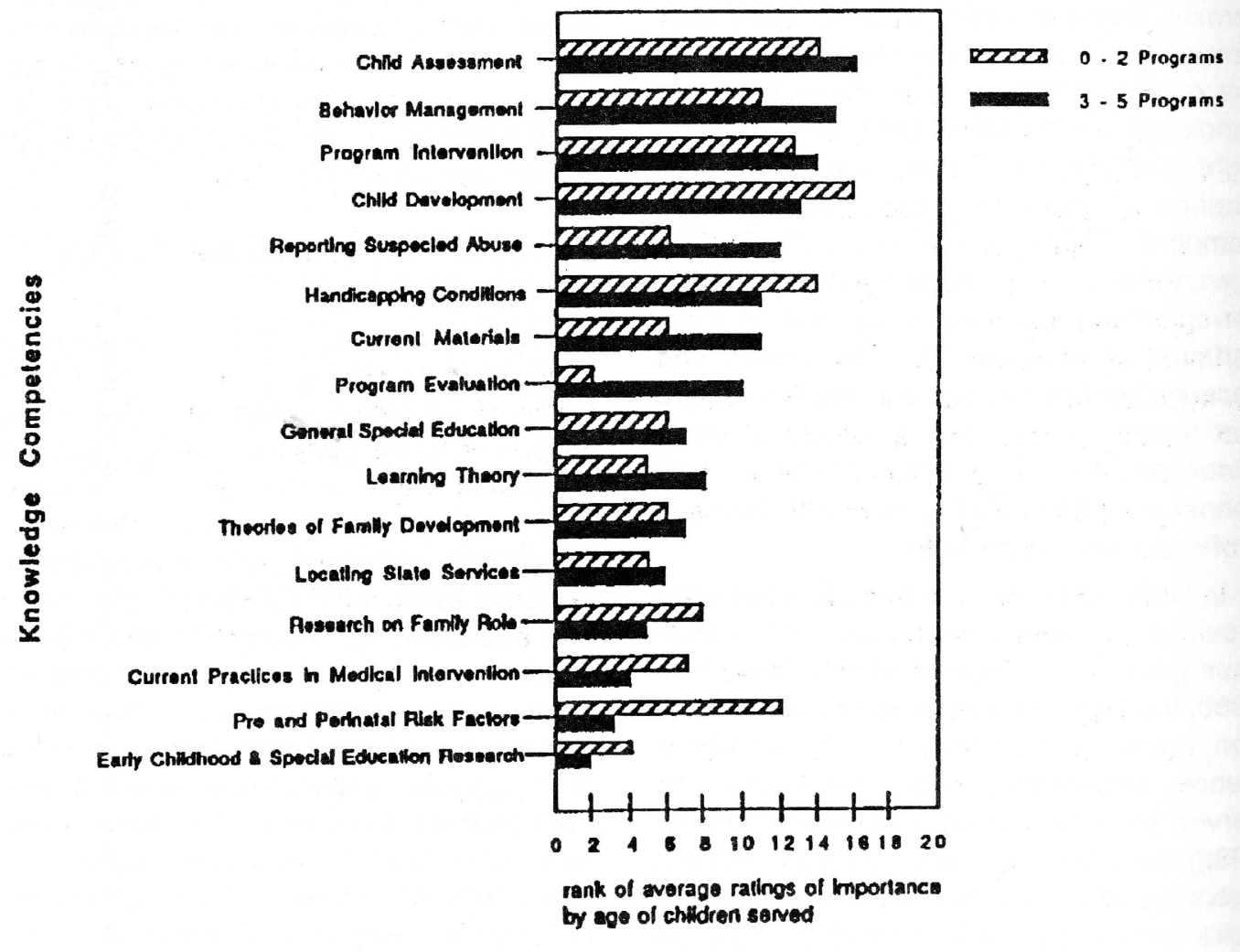




\section{Competencies}

Two questions addressed desirable competencies for personnel serving preschoolers with handicaps. The directors rated the importance of specific knowledge and ability competencies to persons serving children birth through 2 and to those serving children 3 to 5 (shown in Figures 1 and 2). There were no differences between ratings by urban and rural directors. They rated several knowledge and ability competencies as necessary to serve both age groups. These included knowledge of program intervention and ability to implement intervention, ability to use appropriate materials and provide instruction, and knowledge of child development and assessment. There were, however, some notable ranking differences specific to children's age. For example, knowledge of prenatal risk factors was rated as important primarily for birth-through2 service providers, while behavior manage- ment was rated more important for 3-to-5 than birth-through-2 service providers. Although staff serving both age groups were expected to have the ability to use appropriate materials, directors rated knowledge of current materials more important for personnel serving the 3 to 5 age group. Likewise, they rated knowledge of general special education and learning theory more important for personnel serving the three to five age group, probably reflecting the types of services more frequently provided for these children.

There was a discrepancy between the Utah program directors' ratings of ability competencies and those reported by others. Linder (1982) examined competencies required in early intervention programs in all 50 states and found an emphasis in communicating findings to parents and professionals. In a literature review of competencies, Smith and Powers (1987) found several consistently-

Figure 2: Program Directors' Ratings of Desirable Ability Competencies for Staff by Age of Children Served.

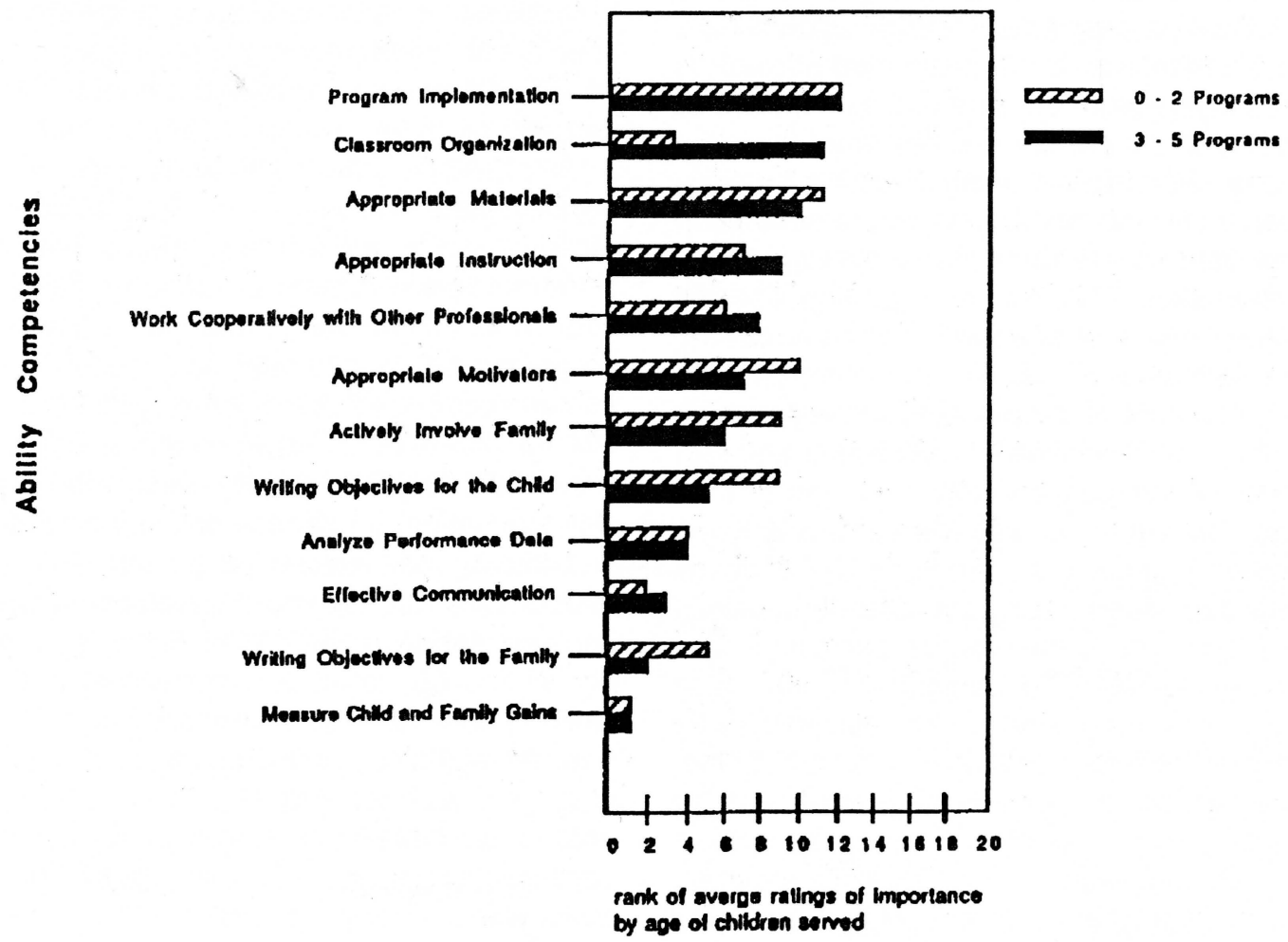


emerging general categories. These included child development (typical and atypical) and family issues. McCollum (1987) studied competencies of early childhood service providers in the state of Illinois; providers serving infants and toddlers reported that teaching parents to work with their children and implementing activities with individual children were of primary importance. Those serving preschoolers reported that the ability to implement individual and group activities was the most-needed skill. While the authors of previous studies reported that working with and communicating with families was most important, the Utah providers ranked knowledge of family theory and family research, writing obiectives for families, and family involvement in the lower half of the competencies necessary to serve infants and toddlers as well as preschoolers.

\section{Implications for Provision of Training}

These findings have implications for personnel preparation. First, the similarities and differences between programs for infants and toddlers and those for preschoolers must be taken into account in designing training and certification programs. Consideration should be given to a core curriculum that addresses the entire age range plus courses specific to each population. Second, the Utah directors ranked working and communicating with parents and team and interagency cooperation less important than did those polled in previous studies. The low rankings suggest that some personnel need information about the requirements of P.L. 99-457 regarding the development of individualized family service plans, multidisciplinary assessment and provision of services, and interagency coordination. The survey results were particularly important to faculty at Utah State University as they developed a program (described below) to prepare early intervention personnel. The survey indicated that personnel in rural areas were less likely than urban residents to be certified. Hence, coursework should somehow be made available to them. Moreover, the survey was a source of information about content that might be included in the program, because program directors either affirmed the importance of certain knowledge and compe- tence or did not, apparently, recognize that certain knowledge and competencies are pertinent to service delivery in order to comply with the legal mandate.

\section{Training Preservice Teachers at the University and in the Field}

In response to the need to prepare teachers to provide early intervention service (though not in direct response to the survey), a program to provide training at the bachelor's and master's levels has been established in the Department of Special Education at Utah State University. The program's primary goal is to provide preservice training for students. In a rural state, however, not all personnel can avail themselves of training on campus, since many are already involved in early intervention. Hence, the program was organized to be accessible to students in various geographic areas, as described below.

\section{Content}

Prior to establishing the program, faculty examined teacher competencies required in states such as lowa (lowa State Office of Education, n.d.) that certified early childhood special educators prior to the passage of P.L. 99-457. They also examined competencies adopted by other universities (Fox, Urquhart, \& Vail, 1986; McRae, 1986) and professional organizations (see, for example, McCollum, McLean, McCartan, \& Kaiser, 1989). The resultant program content included the knowledge and competencies that the surveyed program directors had rated as important and content recognized as important by other early intervention experts: (a) normal and atypical growth and development, (b) assessment and skill evaluation, (c) service delivery program and interagency resources, (d) instructional methods, (e) curriculum, (f) development and implementation of individual family service plans, and (g) parental communication and working with families. In recognition of the need for multidisciplinary training, coursework was required in several departments: family and human development, elementary education, psychology, and special education. Moreover, practica were required in the special education, elementary education, and family 
and human development departments.

\section{Alternative Course Delivery Systems}

Because the state of Utah implemented the provisions of P.L. 99-457 in every school district at the beginning of the 1988-89 school year, the need for inservice as well as preservice early childhood special education was urgent. Teachers with special education or early childhood certification newly hired to teach preschool children with handicaps often lacked experience with young children and their families or with learners with handicaps. A number of experienced teachers of preschool children with handicaps were not certified in any area. The early childhood special education faculty responded to the need to provide training across geographic areas by adopting several course delivery systems: (a) televised classes over the University slow scan network; (b) off-campus classes through traditional University Extension sites; and (c) classes delivered to all early childhood personnel in individual school districts.

The Utah State University slow scan television network, COMNET, extends to 11 primarily rural sites across the state. Each is equipped with a studio classroom. The instructor remains at the university and her lectures are simultaneously received at each site. The students see the instructor on a television monitor in serial still frames (similar to slides that change every few seconds), not in motion video. Voice communication is live. Students and instructor may talk at any time using a microphone. The instructor can use overheads, write on an electronic blackboard, transmit (or receive) print information via a fax system and show prearranged films or videotapes.

This system is practical because the cost and time of travel to provide extension classes throughout the state is prohibitive; the telecommunications system virtually eliminates the need for travel. Moreover, the COMNET system can accommodate small numbers of participants at centers in various geographic areas. Together, these participants constitute a sizable group. Thus, training can be economically extended to rural and remote areas.

The second course delivery system is off- campus extension courses. Extension courses require the instructor to travel about the state, but allow the program to reach students in population centers away from the university. Because these sites are distributed across the state, they are more accessible to rural residents than the main university campus.

The third delivery system is a collaborative effort with school districts. Classes can be offered in larger districts having sufficient numbers of personnel in need of training. Instructors may modify content to some extent to address the individual needs of staff. Staff from a variety of disciplines can participate, enhancing team functioning. Moreover, when supervisors as well as staff participate, all are exposed to similar content and supervisors are better prepared to assist their staff members.

A major challenge in reaching out to districts and individuals in rural areas is the cost in faculty time and travel to provide practicum supervision to individuals in distant locations. The Utah State program has developed supervisory competencies and procedures to train supervisors in various geographic areas. Supervisors use common measurement procedures and report frequently to faculty to assure that personnel learn to appropriately apply didactic course content. They generally conduct field supervision in participants' own classrooms. In addition, faculty have developed supervision methods using videotapes (Fiechtl \& Rule, 1990). Teachers in rural areas videotape their classes, send the tapes to faculty members for critique, and receive feedback via mail or telephone.

\section{Summary}

The passage of Public Law 99-457 has challenged teacher educators to prepare personnel to serve preschool children with handicaps. A survey of personnel employed in early intervention programs defined particular training needs: (a) to extend training to persons serving, but not certified to teach young children with handicaps; and (b) to provide basic content as well as content specific to the birththrough-2 and 3-to-5 age groups. This paper has described how a personnel preparation program was organized to address this chal- 
lenge. In a rural state, it is critical to extend training to geographic areas distant from universities. This training requires a departure from traditional on-campus, within-department personnel preparation practices

\section{References}

Brown, C., Campbell, P., Thiele, J. E., \& Hebbelar, K. (1988, November). What's happeninq in Washington in early childhood: Part II: An overview of early childhood issues in the Office of Special Education Programs. U. S. Department of Education. In S. Fowler (Chair). Symposium at the International Early Childhood Conference on Children with Special Needs, Nashville, TN.

Education of the Handicapped Act Amendments of 1986 (P.L. 99-457). House Report No. 99-860. Washington, DC: U.S. House of Representatives.

Fiechtl, B., \& Rule, S. (1990, March). Telecommunications in special education training. Paper presented to Annual Conference, American Council on Rural Special Education, Tucson, AZ.

Fox, M.H., Urquhart, M., \& Vail, C. O. (1986, November). A review of competencies for teachers of young handicapped or at-risk children and infants. Paper presented to Teacher Education Division Conference, Council for Exceptional Children, Atlanta, GA.

Helge, D. (1987). Recruiting and retaining faculty from a distance. In D. C. Robinson \& R. Gall (Eds.) $A$ telecommunications manual for special education needs in remote and rural areas (pp. 77-94). Eugene, OR: Western Regional Resource Center.

lowa State Office of Education (n.d.) lowa preschool handicapped certification requirement in effect 1981 to September 30. 1988. Des Moines: Department of Special Education.

Linder, T. (1982). A national study of competencies for early childhood special education. Education and Psychological Research, 2, 31-42.

McCollum, J. (1987). Early interventionists in infant and early childhood programs: A comparison of preservice training needs. Topics in Early Childhood Special Education, 7(3), 24-35.

McCollum, J., McLean, M., McCartan, K., \& Kaiser, C. (1989). Recommendations for certification of early childhood special educators. Journal of Early Intervention, 13(3), 195-211.

McRae, H. W. (1986, November). Makinq it work: Interdisciplinary/interaqencyapproach to teacher traininq proqrams for the preschool handicapped. Paper presented to Teacher Education Division Conference, Council for Exceptional Children, Atlanta, GA.

Meisels, S. J., Harbin, G., Modigliani, K., \& Olson, K. (1988). Formulating optional state early childhood intervention policies. Exceptional Children, 55(2), 159-165.
Smith, B., \& Powers, C. (1987). Issues related to developing state certification policies. Topics in Early Childhood Special Education, 7(3), 2-23.

Utah State Board of Education (1989, July). Teacher Certification Requirement Standards. Utah State Office of Education.

\section{Author Notes}

This work was supported in part by Grant No. G008715057, U.S. Department of Education, Office of Special Education and Rehabilitative Services and by a contract with the Utah Office of Education. No official endorsement of either agency should be inferred. 